\title{
Evaluation, treatment, and surveillance of neurogenic detrusor overactivity in spinal cord injury patients
}

\author{
Ali Alsulihem ${ }^{1,2}$, Jacques Corcos ${ }^{1}$ \\ 'Department of Urology, Jewish General Hospital, McGill University, 3755 Côte-Sainte-Catherine Road, Pavillion E. Montreal, \\ QC, H3G 0C7, Canada \\ 2Department of Urology, Prince Sultan Military Medical City, P.O. Box 7897, Riyadh 11159, Saudi Arabia.
}

Correspondence to: Prof. Jacques Corcos, Department of Urology, Jewish General Hospital, McGill University, 3755 CôteSainte-Catherine Road, Pavillion E. Montreal, QC, H3G OC7, Canada. Email: jcorcos@jgh.mcgill.ca

How to cite this article: Alsulihem A, Corcos J. Evaluation, treatment, and surveillance of neurogenic detrusor overactivity in spinal cord injury patients. Neuroimmuno/ Neuroinflammation 2019;6:13. http://dx.doi.org/10.20517/2347-8659.2019.007

Received: 1 Aug 2019 First Decision: 23 Sep 2019 Revised: 28 Oct 2019 Accepted: 30 Oct 2019 Published: 8 Nov 2019

Science Editor: Swapan K. Ray Copy Editor: Jing-Wen Zhang Production Editor: Tian Zhang

\begin{abstract}
Neurogenic detrusor overactivity is a common urodynamic finding in patients with supra-sacral spinal cord injury. Early evaluation, stepped management, and close follow-up reduce the risk of upper urinary tract deterioration, renal failure and incontinence. In this article, we aim to outline the modern pathway of the management of this complex disease. Evaluation of patients with history, physical examination, renal function assessment, cystoscopy, and urodynamic study are essential. Management of neurogenic detrusor overactivity with adequate bladder drainage, medical therapy, intradetrusor botulinum injections, and surgery can be offered in a stepwise manner. Follow-up after specific interventions should be done in a timely fashion to detect treatment response and to avoid complications of poorly managed neurogenic detrusor overactivity.
\end{abstract}

Keywords: Spinal cord injury, neurogenic lower urinary tract dysfunction, neurogenic bladder, neurogenic derusor overactivity, evalutation, treatment, surveillance

\section{INTRODUCTION}

Spinal cord injury (SCI) is one of the most common causes of neurogenic lower urinary tract dysfunction, which affects more than 291,000 individuals in the United States and an annual incidence rate of 17,730 cases $^{[1]}$. It is estimated that $70 \%-84 \%$ of SCI patients have neurogenic lower urinary tract dysfunction ${ }^{[2]}$.

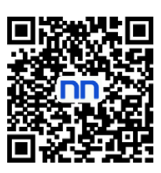




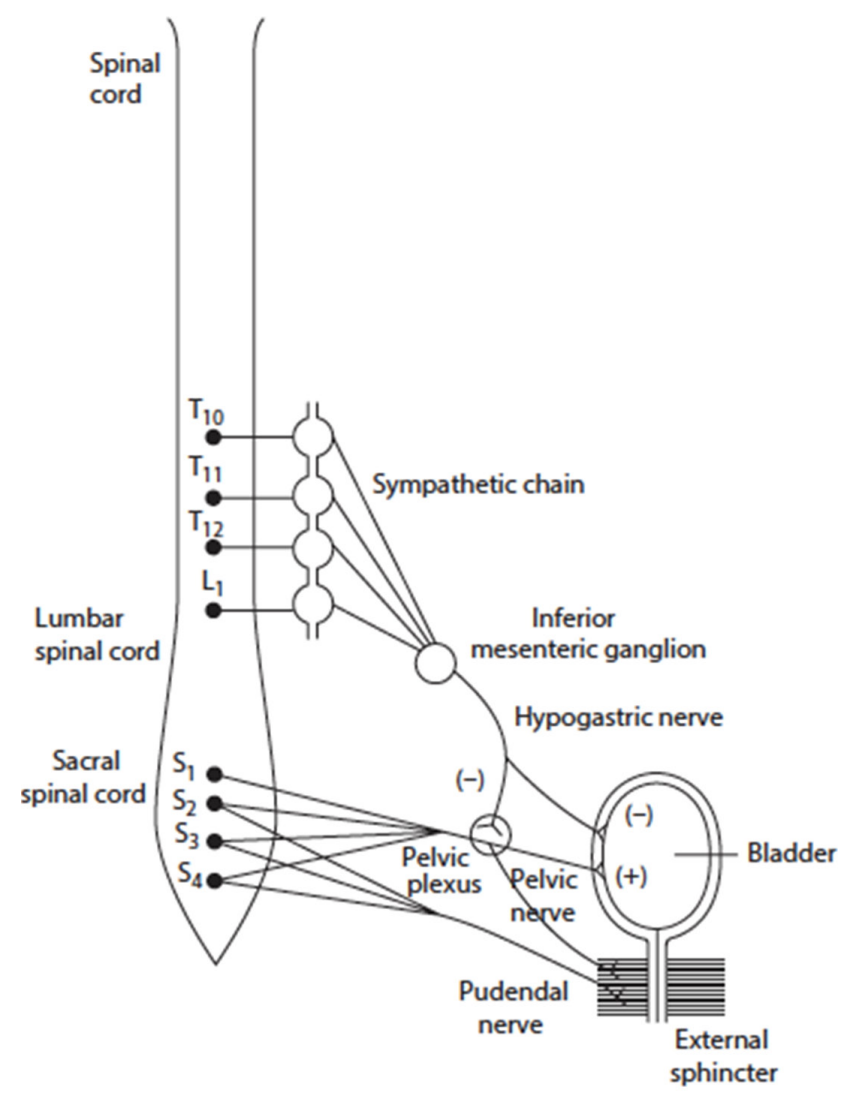

Figure 1. Lower urinary tract innervation (adopted from Aldousari et al. ${ }^{[4]}$ )

The effect of SCI on the lower urinary tract is variable and depends on the level and extent of the injury. Neurogenic detrusor overactivity (NDO) is a common urodynamic finding, reported to be present in up to $95 \%$ of supra-sacral SCI ${ }^{[3]}$. The ultimate goal of the management of neurogenic lower urinary tract dysfunction is to avoid morbidity and mortality secondary to renal failure and/or infections and to improve quality of life by controlling incontinence. The goal of this review article is to present an up-to-date pathway of the evaluation, treatment, and surveillance of NDO in SCI patients.

\section{CLASSIFICATION OF NEUROGENIC LOWER URINARY TRACT DYSFUNCTION IN PATIENTS WITH SCI}

The lower urinary tract is innervated by the hypogastric nerve, the pelvic nerve, and the pudendal nerve. The hypogastric nerve carries sympathetic innervation from spinal level T10-L1, while pelvic and pudendal nerves carry parasympathetic (pelvic), and motor and sensory innervation (pudendal) from the sacral spinal cord (S2-S4) [Figure 1] $]^{[4]}$. Lower urinary tract dysfunction often follows certain patterns, based on the level of the injury, which can be classified into supra-pontine, infra-pontine supra-sacral, sacral, or infra-sacral ${ }^{[5]}$. The supra-sacral injury often results in NDO and infra-pontine supra-sacral lesions often result in detrusor-sphincter dyssynergia [Figure 2] ${ }^{[5]}$. SCI at the vertebral level of T11 may cause sacral nerve damage which may cause underactive detrusor. Injury at the vertebral level of T7 may result in NDO. Injury in vertebral levels between T8 and T10 can generate either hypotonic or overactive detrusor ${ }^{[6]}$. It should be noted that those patterns do not happen in all patients, and further urological evaluation is mandatory to all patients to determine the exact neurogenic lower urinary tract dysfunction regardless of the level of SCI. 


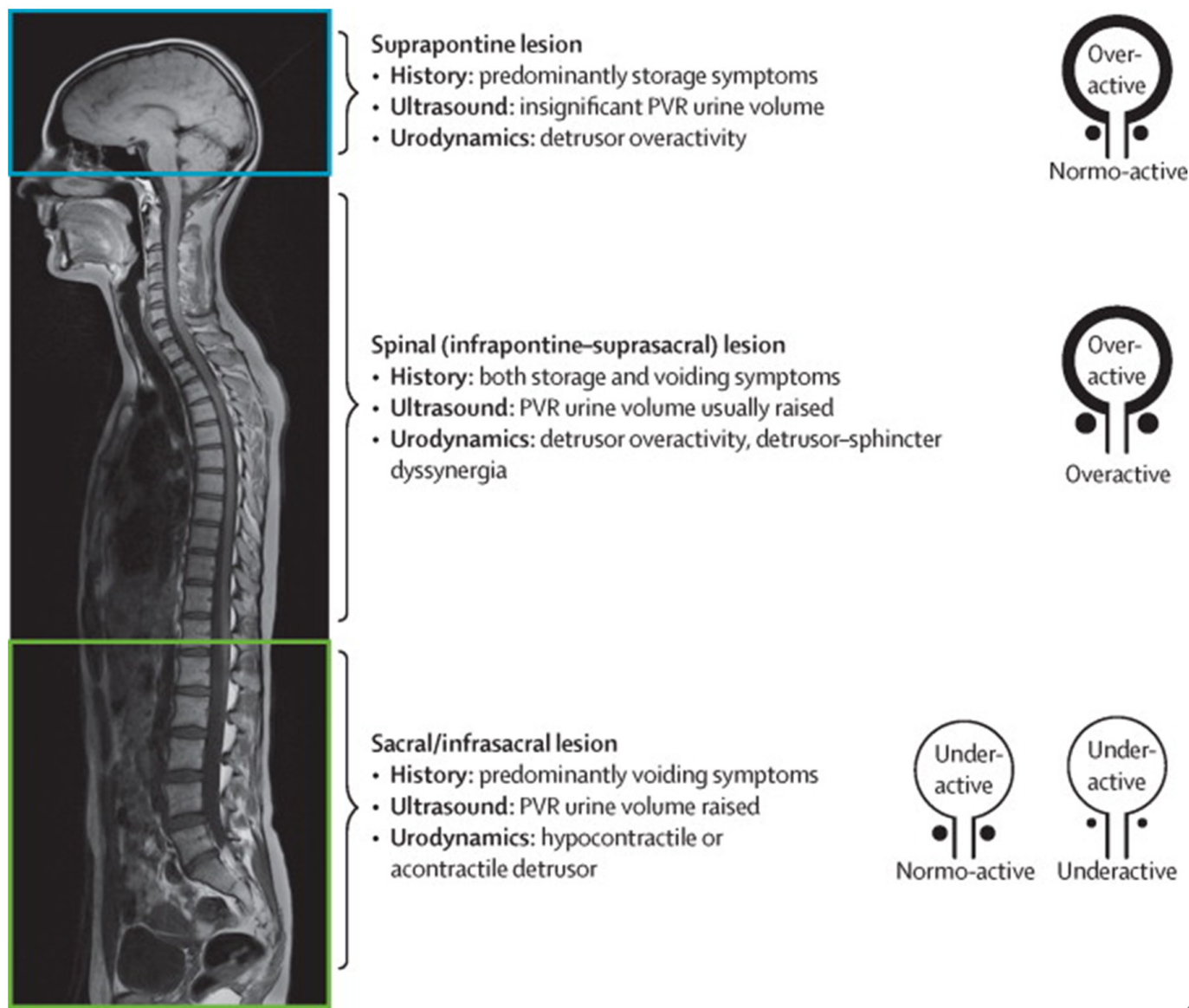

Figure 2. Expected lower urinary tract dysfunction based on the level of neurologic insult (adopted from Panicker et al. ${ }^{[5]}$ )

\section{THE SEQUELAE OF UNTREATED LOWER URINARY TRACT DYSFUNCTION}

The primary functions of the lower urinary tract are: (1) storage of urine under low vesical pressure without leakage; and (2) periodic complete expulsion of urine in socially acceptable time and location. Intact central and peripheral nervous systems are required to achieve these functions ${ }^{[7]}$. SCI and other neurologic disorders frequently affect the functions of the lower urinary tract. Untreated or poorly managed neurogenic lower urinary tract dysfunction may result in: (1) upper urinary tract deterioration resulting in end-stage renal disease; (2) urinary incontinence and urethral damage; (3) recurrent urinary tract infections and urolithiasis; and (4) autonomic dysreflexia ${ }^{[8]}$. In the last half-century, advancement in the management of neurogenic lower urinary tract dysfunction has led to decreased mortality caused by chronic kidney disease, from $50 \%$ in the 1950 s and 1960 s to less than $0.5 \%$ in the $1980 \mathrm{~s}^{[9,10]}$. This emphasized the importance of prompt management of the neurogenic lower urinary tract dysfunction to prevent its sequelae. The 2019 report of the national SCI statistical center has reported a $2.9 \%$ mortality rate secondary to genitourinary diseases in SCI patients ${ }^{[11]}$.

\section{INITIAL EVALUATION AND MANAGEMENT AFTER ACUTE SCI}

\section{Early phase after $\mathrm{SCl}$ (the spinal shock)}

After acute traumatic SCI, a spinal shock phase occurs. The bladder is hypotonic, and urinary retention and overflow incontinence happen in the absence of management. This phase resolves as early as 2 weeks, with an average of 8 weeks, and can be prolonged up to a year ${ }^{[6]}$. The extent and duration of this phase are variable and depend on the extension and the completeness of the spinal injury ${ }^{[12]}$. During this phase, 
conducting a urodynamic study had been considered of limited clinical value ${ }^{[6]}$. Recent evidence has shown the presence of adverse urodynamic findings in those patients in the early phase (within 40 days of the injury) ${ }^{[12]}$. The best management at this phase is to ensure complete bladder drainage by intermittent catheterization (IC) or an indwelling urethral catheter ${ }^{[6-12]}$. Once the patient is stabilized medically, a trial of spontaneous voiding along with post-void residual measurement or self-intermittent catheterization, if the patient cannot void spontaneously, should be tried, while admitted in a rehabilitation facility ${ }^{[12]}$.

\section{Initial urological evaluation}

This will take place at the first consultation and includes: detailed history, physical examination, bladder diary (often catheterization record), post-void residual, urinalysis and culture, renal function assessment, and upper urinary tract imaging ${ }^{[6,8,12]}$. Urodynamic assessment and cystoscopy may be indicated at the first evaluation, depending on the stage of evolution of the neurogenic bladder dysfunction.

\section{History}

Complete medical and surgical history is essential for further evaluation and potential management options and consideration of personalized treatment and follow up. Information about initial trauma and level and completeness of SCI (ASIA score), associated trauma to the urinary tract, and previous lower urinary tract diseases and treatments before spinal cord injury should be documented. The patient's mental and physical capacity should also be noted. History should also include the history of urinary tract infection frequency, symptoms, and treatments. Social history and social support, history of alcoholism or drug abuse are also important for long-term management. History of bowel management, past medical history of acute angle glaucoma, uncontrolled hypertension, and myasthenia gravis should be elicited as it might be a potential contraindication for medications that can be used for the treatment of $\mathrm{NDO}^{[6,12]}$.

\section{Physical examination}

General physical examination is warranted, including a focused examination of the abdomen and genitalia. The ability to perform self-intermittent catheterization should be noted, along with previous abdominal scars or any contraindications that might complicate the insertion of suprapubic catheter insertion. If the clinician is in doubt regarding the patient's capability of performing IC, a consultation in ergotherapy could be very helpful. A focused neurologic exam is required, including anal tone, perineal sensation, and bulbocavernosus reflex ${ }^{[12]}$.

\section{Bladder diary}

A bladder diary is highly recommended but not well studied ${ }^{[13]}$. It can add further information about how frequent the patient is urinating or catheterizing, the amount of urine drained, and the post-void residual. It can add further value in the monitoring of the treatment effect. Components of bladder diary recommended by ICS include voiding time, voided volume, incontinence episodes/use of pads, amount of fluids ingested, urgency, and incontinence degree, along with the method of emptying the bladder ${ }^{[12,14]}$.

\section{Urinalysis and culture}

Urinalysis and microscopy are recommended in the initial visit and in follow up ${ }^{[8,12]}$ to investigate the possibility of UTI in the presence of symptoms with subsequent urine cluture, and it can also detect microscopic hematuria, pyuria, or proteinuria, which might warrant further investigations. The presence of asymptomatic bacteriuria, which is frequent in patients performing IC, is not an indication of antibiotics in the majority of cases.

\section{Post-void residual}

Post void residual measurement is recommended in patients who void spontaneously, or uses valsalva voiding, reflexive voiding/crede voiding and/or condom catheter. The presence of elevated residual might 
Table 1. Poor prognostic features on urodynamics study ${ }^{[6,8,12]}$

\begin{tabular}{ll}
\hline Urodynamic parameter & Abnormal value \\
\hline Compliance & Low compliance $\left(<20 \mathrm{~mL} / \mathrm{cmH}_{2} \mathrm{O}\right)$ \\
Detrusor leak point pressure & Elevated $\left(>40 \mathrm{cmH}_{2} \mathrm{O}\right)$ \\
$\mathrm{NDO}$ & Any degree \\
Detrusor-sphincter dyssynergia & Any type \\
Vesico-ureteric reflex & Any grade \\
Bladder capacity & Reduced $(<200 \mathrm{~mL})$ \\
Sustained prolonged NDO & $>75 \mathrm{cmH}_{2} \mathrm{O}$ \\
\hline
\end{tabular}

NDO: neurogenic detrusor overactivity

trigger further evaluation and different management in those patients, as it increases the risk of UTIs and upper tract deterioration ${ }^{[8]}$.

\section{Urodynamic study}

Urodynamic evaluation is the cornerstone in the evaluation of lower urinary tract dysfunction in SCI patients, but its technique and timing are essential ${ }^{[6,12,14]}$. Several urological authorities and guidelines recommend performing the first study 3 to 6 months after the injury ${ }^{[8,12,14]}$, as recent evidence has shown that adverse urodynamic parameters can appear as early as 40 days after $\mathrm{SCI}^{[15]}$. However, in our practice, the first UDS is performed at the first sign of change in the urinary tract. It could be the onset of a UTI, the beginning of leakage between IC, the appearance or worsening of autonomic dysreflexia, etc. If the first study is done during the spinal shock phase, a repeat study is warranted after the resolution of spinal shock. Video Urodynamics, if available, is considered as the gold standard in the evaluation of patients with NLUTD after SCI, as it can detect vesicoureteric reflux and unmask hidden low bladder capacity and low compliance in patients with VUR ${ }^{[6,12,13]}$. Presence of poor prognostic features [Table 1] in the urodynamic study does require appropriate treatment and follow up urodynamics should be done to monitor the treatment effect and the need for further treatment ${ }^{[6,12]}$. Repeat urodynamic study should be selectively used based on the patient's course over time and with any change in clinical course ${ }^{[13]}$. There is no consensus in which intervals that urodynamics should be repeated in the high-risk population ${ }^{[6,8,12,13]}$.

\section{Imaging}

Renal and bladder imaging is recommended in the initial evaluation of neurogenic bladder patients, preferably an ultrasound, to avoid the risk of exposure to radiation, at three months after the injury ${ }^{[6,8,12,13]}$. The ultrasound can detect complications of neurogenic lower urinary tract dysfunction, such as hydronephrosis, kidney or bladder stones, abnormal bladder morphology such as tumors, thickened bladder wall, or diverticulae, and renal atrophy or scarring ${ }^{[8,12]}$. The follow-up surveillance depends on the presence of adverse findings on urodynamics, which mandates more frequent imaging (every 6-12 months). The imaging might be delayed to 2-3 years in the absence of poor prognostic features on urodynamics ${ }^{[6]}$.

\section{Renal function assessment}

Serum creatinine and estimated glomerular filtration rate are commonly used to assess renal function. It is less accurate than other methods such as creatinine clearance and nuclear GFR. Monitoring the changes of serum creatinine within the normal range is essential. It should be kept in mind that those patients might have less muscle mass, and GFR reduction might not reflect largely on serum creatinine level. Initial creatinine level and periodic follow-up are recommended, especially with unfavorable features on urodynamics, hydronephrosis, and febrile urinary tract infections ${ }^{[6,8,12,13]}$.

\section{Cystoscopy}

Cystoscopy is an important, office-based evaluation of the lower urinary tract. It can detect bladder outlet obstruction due to urethral stricture or prostatic hypertrophy, and bladder abnormalities such as bladder 
Table 2. Overview of management approach to neurogenic lower urinary tract dysfunction and NDO

\begin{tabular}{|c|c|}
\hline Management Lines & Options \\
\hline Assisted bladder drainage & $\begin{array}{l}\text { Clean intermittent self catheterization, indwelling suprapubic catheters, indwelling } \\
\text { urethral catheters }\end{array}$ \\
\hline Systemic medications to reduce intravesical pressure & Anticholenergics, beta-3 agonists \\
\hline Intra-detrusor botulinum toxin A injection & Onabotulinum toxin $\mathrm{A}$, abobotulinium toxin $\mathrm{A}$ \\
\hline Sacral nerve stimulation & $\mathrm{N} / \mathrm{A}$ \\
\hline Surgical treatment & Bladder augmentation, urinary diversion \\
\hline
\end{tabular}

NDO: neurogenic detrusor overactivity

tumor, trabeculation, bladder tumors, and bladder stones. Although the value of cystoscopy at initial evaluation has been questioned ${ }^{[8,12,13,16]}$, We recommend doing cystoscopy at initial evaluation, and as diagnostic tool for patients who present with difficult catheterization to diagnose urethral stricture and false passage, or when presenting with recurrent urinary tract infection, increased incontinence, bladder spasticity and/or dysreflexia for possibility of finding a bladder stone. It should be noted that cystoscopy is a mandatory investigation for hematuria workup ${ }^{[7]}$. Screening cystoscopy for patients on a chronic indwelling catheter is recommended for early diagnosis of bladder cancer, although the value of such an approach has not been proven ${ }^{[17]}$.

\section{Treatment of NDO}

The goals of NDO treatment are to reduce its risks on the urinary tract by reducing detrusor storage pressures, increasing bladder capacity, improving incontinence, and improving patient's quality of life. Table 2 summarizes management strategies of neurogenic lower urinary tract dysfunction and NDO. Treatment effect monitoring in a timely fashion (2-3 months) is essential to avoid long term complications of the poorly managed bladder ${ }^{[12]}$.

\section{Adequate bladder drainage using catheterization}

It is estimated that around $75 \%$ of SCI injury patients cannot void spontaneously ${ }^{[18]}$, which mandate assisted bladder drainage. Types of bladder drainage include: (1) clean intermittent self-catheterization (CISC); (2) indwelling suprapubic catheterization; and (3) indwelling urethral catheterization.

The patient should be aware of risks and benefits of the several methods of bladder drainage and advised to avoid indwelling urethral catheters if possible, to reduce risks of urinary tract infections, bladder stone formation, and urethral erosion ${ }^{[13,19]}$. It is recommended to keep patients, who cannot empty their bladder spontaneously, on CISC ${ }^{[8,12,13]}$. The frequency of CISC depends on many factors, such as fluid intake, bladder volume, and urodynamic parameters, and is recommended to do it 4 to 6 times/day ${ }^{[20]}$. CISC teaching is preferably done early during the rehabilitation phase, to evaluate the patient ability to perform it, and to evaluate for the possibility of spontaneous voiding ${ }^{[12]}$.

CISC, although considered as the gold standard of assisted bladder drainage mechanism, have several limitations [Table 3], that treating physician should carefully assess and adjust those limitations if possible or shift the patient to alternative drainage options ${ }^{[18,21]}$.

If CISC cannot be performed [Table 3], alternative management options include indwelling suprapubic catheterization or indwelling urethral catheterization. Suprapubic catheters are generally preferred over urethral catheters, with some studies supporting that preference. Suprapubic catheters have advantages over urethral catheters, which include the elimination of risks of urethral erosions and iatrogenic hypospadias ${ }^{[22]}$, fewer risks of epididymitis and enable patients to perform sexual activities ${ }^{[23]}$. Some evidence showed a decreased risk of urinary tract infection with suprapubic catheters ${ }^{[24-26]}$. Indwelling catheters (urethral and 
Table 3. Limitations of $\mathrm{CISC}^{[18,19]}$

\begin{tabular}{ll}
\hline Limitations of CISC & \multicolumn{1}{c}{ Examples } \\
\hline Limited upper extremity motor function & Quadriplegia \\
Anatomic limitation & Inability to reach urethra due to obesity or in female patients \\
Limited functional bladder capacity (below $300 \mathrm{~mL})$ & Poor bladder compliance or untreated NDO \\
Obstructed urethra & Severe urethral damage, urethral stricture, non-relaxing sphincter \\
\hline
\end{tabular}

CISC: continuous intermittent self-catheterization; NDO: neurogenic detrusor overactivity

suprapubic) should be changed every 4-6 weeks, and the use of silicon catheters is recommended ${ }^{[22]}$. It should be kept in mind that indwelling catheters (urethral and suprapubic) associated with increased risk of bladder cancer (up to $10 \%$ ) in the long term ${ }^{[27,28]}$, therefore, screening cystoscopy has been recommended to start 10 years after indwelling catheter insertion. In cases of increased urethral leakage, recurrent urinary tract infection, or increased sediments and frequent catheter blockages, cystoscopy is also recommended to rule out the presence of bladder stones ${ }^{[22,28]}$.

Therefore, we discourage the utilization of indwelling urethral catheterization and prefer the use of suprapubic catheters as a second-line option if clean IC (first line option) is not a feasible option for SCI patient.

Systemic medications to treat neurogenic detrusor over-activity

Systemic medications have been used to reduce detrusor storage pressure, increase bladder capacity, and improve urinary incontinence ${ }^{[8,12,13,22]}$. The most commonly used medications are anticholinergics (antimuscarinics), and beta-3 agonists. Systemic medications, along with CISC, constitute the first-line management of NDO in SCI patients ${ }^{[13,29]}$. Follow up after starting the systemic medication is warranted, which includes follow-up of symptoms improvement and urodynamic study in 3 months ${ }^{[12]}$.

Antimuscarinics (anticholinergics), antimuscarinic receptor antagonists are the most commonly used medications in the treatment of $\mathrm{NDO}^{[8,12]}$. Several medications in this class are available and in multiple forms [Table 4]. It is expected to decrease the maximum detrusor pressure by $30 \%-40 \%$, and to increase the bladder capacity by $30 \%-40 \%{ }^{[30]}$. It increases the maximum cystometric capacity by $49.79 \mathrm{~mL}$ and lowers detrusor pressure at the strongest contraction by $38.3 \mathrm{~cm} / \mathrm{H}_{2} \mathrm{O}^{[31]}$. The possible adverse reactions should be monitored, along with improvement in symptoms and urodynamic parameters. Common adverse reactions include dry mouth, dry eyes, constipation, blurred vision, cognitive impairment (confusion), prolonged Q-T interval, and headache ${ }^{[29]}$. Anticholinergics should be avoided in patients with glaucoma, myasthenia gravis, gastrointestinal obstruction, and severe ulcerative colitis ${ }^{[32]}$. Another form of anticholinergics administration includes intravesical administration of $10 \mathrm{~mL}$ of $0.1 \%$ of oxybutynin three times daily, which shown to be equally effective to oral oxybutynin and with fewer systemic side effects ${ }^{[33]}$. The choice of specific anticholinergic medication is based on availability, tolerability, and side effect profile [Table 4].

Beta-3 agonists, mirabegron, the commercially available beta-3 agonist to treat detrusor overactivity, has been introduced recently. It acts on beta-3 receptors on the detrusor muscle to induce relaxation of the detrusor muscle ${ }^{[29]}$. Its use in NDO has been shown to increase the volume at the first detrusor contraction and to improve bladder compliance, with a non-significant increase in bladder capacity when compared to placebo ${ }^{[34]}$. The usual dose of Mirabegron is $25-50 \mathrm{mg} / \mathrm{day}$, which can be increased to $100 \mathrm{mg} / \mathrm{day}^{[33]}$. The possible adverse reactions include hypertension, urinary tract infection, and headache ${ }^{[29]}$. The use of mirabegron is currently limited in neurogenic bladder patients, as limited evidence exists to support its use in this population ${ }^{[8,31]}$. It might be considered as an alternative in patients with contraindication to using anticholinergics, or as an add-on treatment to anticholinergics ${ }^{[35,36]}$. 
Table 4. Common antimuscarinic medications used in the treatment of NDO ${ }^{[12,29,60]}$

\begin{tabular}{|c|c|c|c|c|}
\hline Name of drug & Form & Dosage & Advantages & Special precautions/disadvantages \\
\hline \multirow[t]{3}{*}{ Oxybutynin } & $\begin{array}{l}\text { Oral, immediate } \\
\text { release }\end{array}$ & $\begin{array}{l}\text { 10-30 mg divided in } \\
\text { 2-3 times/day }\end{array}$ & $\begin{array}{l}\text { Antimuscarinic action with direct } \\
\text { muscle relaxing effect and some local } \\
\text { anesthetic effect } \\
\text { No renal or hepatic dose adjustment }\end{array}$ & \multirow[t]{3}{*}{ Highest side effect profile } \\
\hline & $\begin{array}{l}\text { Oral, extended- } \\
\text { release }\end{array}$ & Up to $30 \mathrm{mg} /$ day & Avoids multiple daily dosing & \\
\hline & Transdermal & $\begin{array}{l}3.9 \mathrm{mg} / \text { day patch, } 2 \\
\text { patches/week }\end{array}$ & $\begin{array}{l}\text { Lower anticholinergic side effect (avoid } \\
\text { the first-pass metabolism) }\end{array}$ & \\
\hline \multirow[t]{2}{*}{ Tolterodine } & $\begin{array}{l}\text { Oral, immediate } \\
\text { release }\end{array}$ & $\begin{array}{l}\text { 2-8 mg divided twice } \\
\text { per day }\end{array}$ & $\begin{array}{l}\text { Non-selective anticholinergic } \\
\text { Lower selectivity to the parotid gland }\end{array}$ & $\begin{array}{l}\text { Needs dose reduction in renal } \\
\text { impartment and hepatic dysfunction }\end{array}$ \\
\hline & $\begin{array}{l}\text { Oral, extended- } \\
\text { release }\end{array}$ & $2-8 \mathrm{mg} /$ day & Avoids multiple daily dosing & $\begin{array}{l}\text { Reduce dose in renal impairment and } \\
\text { hepatic dysfunction }\end{array}$ \\
\hline Propiverine & Oral & 30-45 mg/day & $\begin{array}{l}\text { Non-selective anticholinergic \& } \\
\text { musculotropic } \\
\text { Less dry mouth }\end{array}$ & $\begin{array}{l}\text { Reduce dose in severe renal impairment } \\
\text { (30 mg/day) } \\
\text { Avoid in severe hepatic dysfunction }\end{array}$ \\
\hline \multirow[t]{2}{*}{ Trospium } & $\begin{array}{l}\text { Oral, immediate } \\
\text { release }\end{array}$ & 20 mg twice per day & $\begin{array}{l}\text { Does not cross BBB } \\
\text { Minimal central side effect } \\
\text { Minimal hepatic metabolism }\end{array}$ & \multirow{2}{*}{$\begin{array}{l}\text { Avoid use in moderate to severe hepatic } \\
\text { dysfunction } \\
\text { Maximum dose of renal impairment is } \\
30 \mathrm{mg} / \text { day }\end{array}$} \\
\hline & $\begin{array}{l}\text { Oral, extended- } \\
\text { release }\end{array}$ & 60 mg once per day & $\begin{array}{l}\text { Lower dry mouth than immediate- } \\
\text { release form }\end{array}$ & \\
\hline Solifenacin & Oral & 5-10 mg once per day & $\begin{array}{l}\text { Modest selectivity to } M 3 \text { over } M 1 \& \\
\text { M2 receptors } \\
\text { Lower dry mouth than oxybutynin }\end{array}$ & $\begin{array}{l}\text { Use low dose }(5 \mathrm{mg}) \text { in renal } \\
\text { impairment }(\mathrm{CrCl}<30) \text { and moderate } \\
\text { hepatic dysfunction } \\
\text { Avoid use in severe hepatic dysfunction }\end{array}$ \\
\hline Darifenacin & Oral & 7.5-15 mg once per day & $\begin{array}{l}\text { Relative selectivity to } \mathrm{M} 3 \text { receptor } \\
\text { No dose adjustment in renal } \\
\text { impairment }\end{array}$ & $\begin{array}{l}\text { No studies in NDO } \\
\text { Use is not recommended in severe } \\
\text { hepatic dysfunction }\end{array}$ \\
\hline Fesoterodine & Oral & 4-8 mg once per day & $\begin{array}{l}\text { Selective } M 2, M 3 \text { receptor antagonist } \\
\text { Equal affinity to } M 2 \text { and } M 3 \text { receptors } \\
\text { Poor penetration to } B B B\end{array}$ & $\begin{array}{l}\text { Not studied in NDO } \\
\text { Use is not recommended in severe } \\
\text { hepatic dysfunction } \\
\text { Dose is reduced to } 4 \mathrm{mg} / \text { day in renal } \\
\text { impairment }\end{array}$ \\
\hline
\end{tabular}

BBB: blood-brain barrier; NDO: neurogenic detrusor overactivity; $\mathrm{CrCl}$ : creatinine clearance

\section{Intravesical injection of botulinum toxin}

Onabotulinumtoxin A (Botox) is a neurotoxin that causes detrusor muscle relaxation by preventing the release of acetylcholine on pre-synaptic parasympathetic nerve ending, resulting in a reduction of $\mathrm{NDO}$, incontinence episodes, and increase of bladder capacity ${ }^{[37]}$. It has been approved as a treatment of neurogenic detrusor overactivity in SCI patients since $2011^{[38]}$. The usual dose is 200 units, injected into detrusor muscle in 20 sites delivered via cystoscope ${ }^{[37]}$. It increases the bladder capacity by $134.75 \mathrm{~mL}$, volume at first involuntary detrusor contraction with a median difference of $163.42 \mathrm{~mL}$, reduced maximal detrusor pressure at a median of $30.48 \mathrm{~cm} / \mathrm{H}_{2} \mathrm{O}$, and reduced urinary incontinence episodes by $12.45 /$ day, in compression to placebo ${ }^{[39]}$. It also improved the bladder compliance and reduced incidence of detrusor overactivity when compared to baseline $(\mathrm{OR}=64.27 ; 95 \% \mathrm{CI}: 12.17-339.28 ; P<0.00001)^{[39]}$.

The possible common adverse effects include urinary tract infections, hematuria, generalized weakness, and urinary retention (which is not a concern in patients using CISC) ${ }^{[37,38]}$. The effect usually lasts approximately nine months, and repeat injection is indicated after the disappearance of its effect ${ }^{[40]}$.

Abobotulinum toxin A (750 IU) is another botulinum toxin that has also been used in the management of NDO with similar outcomes to onabotulinum toxin $\mathrm{A}^{[41]}$. Shifting to abobotulinium toxin A (Dysport) after failed onabotulinum toxin A therapy has been found successful in about $52 \%-57 \%$ of cases ${ }^{[41]}$.

The clinician should evaluate the response of Botulinum Toxin A 2-3 months with symptomatic and 
urodynamic evaluation 2-3 months after the first injection and then if there is a change of clinical course and recurrence of symptoms despite recent injection ${ }^{[12,40]}$.

\section{Sacral nerve stimulation}

Several retrospective and observational studies have evaluated the role of dorsal rhizotomy (sacral deafferentation S2-S4/5), combined with anterior sacral root stimulation in the treatment of NDO ${ }^{[42-45]}$. This treatment has been shown to effectively reduce elevated detrusor pressure, improve compliance, increase bladder capacity, improve urinary incontinence, and achieve voluntary bladder and bowel emptying in patients with complete $\mathrm{SCI}^{[1-44]}$. This technique has a variable success rate in specialized centers but is limited by long-term complications and a high rate of surgical revision. It might be offered by experienced centers and in highly selected patients as a third-line option after failure of previous medical and minimally invasive options ${ }^{[8,13]}$.

\section{Surgical treatment of NDO}

Surgical treatment options are considered when all medical and minimally invasive treatment options have failed to eliminate poor urodynamic parameters [Table 1]. Surgical options include bladder augmentation and urinary diversion.

Bladder augmentation, using a bowel segment, should be considered in patients who failed all medical and minimally invasive management for reduced bladder capacity and $\mathrm{NDO}^{[8,13]}$. It can eliminate urinary incontinence in $75 \%-100 \%$, improve bladder compliance in $69 \%-100 \%$, and improve quality of life in $90 \%$ of patients ${ }^{[8]}$. The addition of a continent catheterizable channel might be considered if the patient cannot catheterize through the urethra ${ }^{[8,46]}$. Contraindications to performing bladder augmentation include bladder malignancy, Chronic kidney disease (creatinine clearance less than $40 \mathrm{~mL} / \mathrm{min}$ ), bowel disease, previous significant bowel resection, inability to do CISC (such as quadriplegia), or unwillingness to perform CISC $^{[8,46]}$. Long term complications include bladder stone formation, metabolic complications, intraperitoneal bladder perforation, urosepsis, vesicoureteric reflux, recurrence of NDO and adenocarcinoma or urothelial carcinoma in up to $6 \%{ }^{[8,46-48]}$. Therefore, lifelong surveillance with cystoscopy is recommended. In case of recurrence of incontinence, video urodynamic is recommended, and in the presence of NDO, treatment with Botox injection into the augmented bladder can be tried before surgical revision or urinary diversion ${ }^{[49]}$.

Urinary diversion, is considered as last resort option in the management of NDO if the patient is unfit or not a candidate for bladder augmentation. Urinary diversion options include continent and incontinent diversion ${ }^{[46]}$.

Continent urinary diversion with continent catheterizable channels is performed when the patient can catheterize but cannot use native bladder due to a severely contracted bladder with severe vesicoureteral reflux or devastated bladder outlet, or bladder malignancy ${ }^{[8,47]}$. It carries a higher risk of long-term metabolic complications. It is contraindicated in patients with chronic kidney disease (creatinine clearance less than $40 \mathrm{~mL} / \mathrm{min}$ ) and in a patient who are not fit for $\mathrm{CISC}^{[8,48]}$.

Incontinent urinary diversion is a last resort option ${ }^{[8,13,49]}$, in which urine is diverted to the skin by using bowel segment (usually ileum) in patients who cannot perform CISC and in patients who are unfit or failed other surgical options ${ }^{[8,13,46]}$. An ileal conduit is a familiar procedure to urologists, the most commonly performed incontinent urinary diversion procedure, and the preferred incontinent urinary diversion procedure ${ }^{[8,46,50]}$. It results in renal function preservation in $88 \%$ to more than $90 \%$ of patients ${ }^{[8,50]}$. Possible complications include ureteral anastomotic stenosis, stomal or incisional hernia, stomal stenosis, bowel obstruction, urinary tract infections and pyelonephritis, urine leak, urolithiasis, and metabolic complications (acidosis) ${ }^{[46,51]}$. Overall major complications can reach up to $11 \%{ }^{[8]}$. 
Other incontinent urinary diversion includes ileovesicostomy, which avoids ureteric reimplantation and cystectomy and related complications but has the disadvantage of leaving a bladder segment, which can increase the risk of malignancy or urethral incontinence ${ }^{[8,46,47,52]}$. It can be considered in select patients. Robust long-term results and quality of life data are lacking ${ }^{[s]}$. Reported complications include impaired bladder emptying, urethral incontinence, stomal stenosis, parastomal hernia, and urolithiasis ${ }^{[8,46,53-56]}$.

Therefore, monitoring patients postoperatively is essential to detect complications, and surveillance is of paramount importance.

\section{Monitoring, follow up, and surveillance}

We recommend regular and tight surveillance after initial management, with clinical history, physical examination, and urodynamic evaluation after initiation of any intervention, to monitor response and to determine successful treatment and need for augmentation of medication dose or considering alternative management option. The time between the visit should be within 2-3 months after the initiation of medications or botulinum toxin A injection ${ }^{[8,12,40]}$. After controlling poor urodynamic features, annual follow up of symptoms, renal function, and upper tract ultrasound are recommended ${ }^{[6,8,13]}$. Repeat urodynamic and cystoscopy is recommended after a change in the clinical course, such as new incontinence or recurrent urinary tract infections ${ }^{[6]}$.

\section{Urinary tract related factors impacting the quality of life in $\mathrm{SCl}$ patients}

Quality of life (QOL) in SCI was found to be associated with a poorly managed urinary tract. Worse QOL scores were found to be associated with urinary incontinence and recurrent UTIs ${ }^{[57-59]}$. Well managed bladder with surgery and indwelling catheters had better QOL scores than patients who use clean IC ${ }^{[58]}$. Worst QOL scores were associated with SCI patients who do not use catheters and leak on diapers ${ }^{[58]}$. This emphasizes the importance of proper management of urinary incontinence in SCI patients to improve their quality of life.

\section{CONCLUSION}

NDO secondary to SCI has a significant impact on patient quality of life, morbidity, and mortality. Early detailed evaluation and timely intervention are of paramount importance to avoid its long-term sequelae. Patients should be aware of the possible risks and benefits of each management option, and physicians should keep patients under close monitoring to act early upon any changes in patients' course of the disease. Research in NDO should continue to address several poorly studies areas in pathophysiology, treatments, and surveillance, as most of the available recommendations in this filed are largely based on retrospective studies.

\section{DECLARATIONS}

\section{Authors' contributions}

Wrote the first draft of the manuscript: Alsulihem A

Reviewed and edited the final manuscript: Corcos J

\section{Availability of data and materials}

Not applicable.

\section{Financial support and sponsorship}

None. 


\section{Conflicts of interest}

Both authors declared that there are no conflicts of interest.

\section{Ethical approval and consent to participate}

Not applicable.

\section{Consent for publication}

Not applicable.

\section{Copyright}

(c) The Author(s) 2019.

\section{REFERENCES}

1. Jain NB, Ayers GD, Peterson EN, Harris MB, Morse L, et al. Traumatic spinal cord injury in the United States, 1993-2012. JAMA 2015;313:2236-43.

2. Manack A, Motsko SP, Haag-Molkenteller C, Dmochowski RR, Goehring EL Jr, et al. Epidemiology and healthcare utilization of neurogenic bladder patients in a US claims database. Neurourol Urodyn 2011;30:395-401.

3. Weld KJ, Dmochowski RR. Association of level of injury and blad $\neg$ der behavior in patients with post-traumatic spinal cord injury. Urology 2000;55:490-4

4. Aldousari S, Corcos J. Simplified anatomy of the vesicourethral functional unit. In: Corcos J, Ginsburg D, Karsenty G, editors. Textbook of the neurogenic bladder. 3rd ed. Boca Raton, FL, USA: CRC Press; 2015. p. 3-8.

5. Panicker JN, Fowler CJ, Kessler TM. Lower urinary tract dysfunction in the neurological patient: clinical assessment and management. Lancet Neurol 2015;14:720-32.

6. Corcos J. Practical guide to diagnosis and follow-up of patients with neurogenic bladder dysfunction. In: Corcos J, Ginsburg D, Karsenty G, editors. Textbook of the neurogenic bladder. 3rd ed. Boca Raton, FL, USA: CRC Press; 2015. p. 443-6.

7. Yoshimura N, Jeong JY, Kim DK, Chancellor MB. Integrated physiology of the lower urinary tract. In: Corcos J, Ginsburg D, Karsenty G, editors. Textbook of the neurogenic bladder. 3rd ed. Boca Raton, FL, USA: CRC Press; 2015. p. 33-47.

8. Kavanagh A, Baverstock R, Campeau L, Carlson K, Cox A, et al. Canadian urological association guidelines: diagnosis, management, and surveillance of neurogenic lower urinary tract dysfunctiont. Can Urol Assoc J 2019;13:E157-76.

9. Donelly J, Hackler RH, Bunts RC. Present urologic status of the World War II paraplegic: 25-Year follow-up. Comparison with sta $\neg$ tus of the 20-year Korean War paraplegic and the 5-year Vietnam paraplegic. J Urol 1972;108:558-62.

10. Webb DR, Fitzpatrick JM, O’Flynn JD. A 15-year follow-up of 406 consecutive spinal cord injuries. Br J Urol 1984;56:614-7.

11. 2018 Annual report - complete public version. National Spinal Cord Injury Statistical Center, Birmingham, Alabama. 4th edition. Available from: https://www.nscisc.uab.edu/ [Last accessed on 30 Oct 2019]

12. Welk B, Schneider MP, Thavaseelan J, Traini LR, Curt A, et al. Early urological care of patients with spinal cord injury. World J Urol 2018;36:1537-44.

13. Groen J, Pannek J, Castro Diaz D, Del Popolo G, Gross T, et al. Summary of European Association of Urology (EAU) guidelines on neuro-urology. Eur Urol 2016;69:324-33.

14. Bright E, Cotterill N, Drake M, Abrams P. Developing a validated urinary diary: phase 1. Neurourol Urodyn 2012;31:625-33.

15. Bywater M, Tornic J, Mehnert U, Kessler TM. Detrusor acontractility after acute spinal cord injury-myth or reality? J Urol 2018;199:1565-70.

16. Welk B, Liu K, Shariff SZ. The use of urologic investigations among patients with traumatic spinal cord injuries. Res Rep Urol 2016;8:27-34.

17. Welk B, McIntyre A, Teasell R, Potter P, Loh E. Bladder cancer in individuals with spinal cord injuries. Spinal Cord 2013;51:516-21.

18. Zlatev DV, Shem K, Elliott CS. How many spinal cord injury patients can catheterize their own bladder? The epidemiology of upper extremity function as it affects bladder management. Spinal Cord 2016;54:287-91.

19. McIntyre A, Cheung KY, Kwok C, Mehta S, Teasell RW. Quality of life and bladder management post-spinal cord injury: a systematic review. Appl Res Qual Life 2014;9:1081-96.

20. Wyndaele JJ. Conservative treatment. In: Corcos J, Ginsburg D, Karsenty G, editors. Textbook of the neurogenic bladder. 3rd ed. Boca Raton, FL, USA: CRC Press; 2015. p. 455-66.

21. Binard JE, Persky L, Lockhart JL, Kelley B. Intermittent catheterization the right way! (Volume vs. time-directed). J Spinal Cord Med 1996;19:194-6.

22. Drake MJ, Apostolidis A, Cocci A, Emmanuel A, Gajewski JB, et al. Neurogenic lower urinary tract dysfunction: clinical management recommendations of the neurologic Incontinence committee of the fifth international consultation on incontinence 2013. Neurourol Urodyn 2016;35:657-65.

23. Weld KJ, Dmochowski RR. Effect of bladder management on urological complications in spinal cord injured patients. J Urol 2000;163:768-72.

24. Hennessey DB, Kinnear N, MacLellan L, Byrne CE, Gani J, et al. The effect of appropriate bladder management on urinary tract infection rate in patients with a new spinal cord injury: a prospective observational study. World J Urol 2019;37:2183-8. 
25. Hunter KF, Bharmal A, Moore KN. Long-term bladder drainage: Suprapubic catheter versus other methods: a scoping review. Neurourol Urodyn 2013;32:944-51.

26. Esclarín De Ruz A, García Leoni E, Herruzo Cabrera R. Epidemiology and risk factors for urinary tract infection in patients with spinal cord injury. J Urol 2000;164:1285-9.

27. Sugimura T, Arnold E, English S, Moore J. Chronic suprapubic catheterization in the management of patients with spinal cord injuries: analysis of upper and lower urinary tract complications. BJU Int 2008;101:1396-400.

28. Caremel R, Feifer A, Corcos J. Management of neurogenic bladder with suprapubic cystostomy. In: Corcos J, Ginsburg D, Karsenty G, editors. Textbook of the neurogenic bladder. 3rd ed. Boca Raton, FL, USA: CRC Press; 2015. p. 467-71.

29. Aharony S, Corcos J. Systemic and intrathecal pharmacologic treatment. In: Corcos J, Ginsburg D, Karsenty G, editors. Textbook of the neurogenic bladder. 3rd ed. Boca Raton, FL, USA: CRC Press; 2015. p. 473-88.

30. Madersbacher H, Murtz G, Stohrer M. Neurogenic detrusor overactivity in adults: a review on efficacy, tolerability, and safety of oral anti-muscarinics. Spinal Cord 2013;51:432-41.

31. Romo PGB, Smith CP, Cox A, Averbeck MA, Dowling C, et al. Non-surgical urologic management of neurogenic bladder after spinal cord injury. World J Urol 2018;36:1555-68.

32. Munjuluri N, Wong W, Yoong W. Anticholinergic drugs for overactive bladder: a review of the literature and practical guide. Obstet Gynecol 2007;9:9-14.

33. Schroder A, Albrecht U, Schnitker J, Reitz A, Stein R. Efficacy, safety, and tolerability of intravesically administered $0.1 \%$ oxybutynin hydrochloride solution in adult patients with neurogenic bladder: a randomized, prospective, controlled, multicentre trial. Neurourol Urodyn 2016;35:582-8.

34. Krhut J, Borovička V, Bílková K, Sýkora R, Míka D, et al. Efficacy and safety of mirabegron for the treatment of neurogenic detrusor overactivity - prospective, randomized, double-blind, placebo-controlled study. Neurourol Urodyn 2018;37:2226-33.

35. Soebadi MA, Hakim L, Van der Aa F, De Ridder D. Real-life data on mirabegron in neurogenic bladder dysfunction. Urol Int 2019;103:195-201.

36. Han SH, Cho IK, Jung JH, Jang SH, Lee BS. Long-term efficacy of mirabegron add-on therapy to antimuscarinic agents in patients with spinal cord injury. Ann Rehabil Med 2019;43:54-61.

37. Smith CP. Intravesical pharmacologic treatment for neurogenic detrusor overactivity. In: Corcos J, Ginsburg D, Karsenty G, editors. Textbook of the neurogenic bladder. 3rd ed. Boca Raton, FL, USA: CRC Press; 2015. p. 489-501.

38. Linsenmeyer TA. Use of botulinum toxin in individuals with neurogenic detrusor overactivity: state of the art review. J Spinal Cord Med 2013;36:402-19.

39. Li GP, Wang XY, Zhang Y. Efficacy and safety of onabotulinumtoxinA in patients with neurogenic detrusor overactivity caused by spinal cord injury: a systematic review and meta-analysis. Int Neurourol J 2018;22:275-86.

40. Weckx F, Tutolo M, De Ridder D, Van der Aa F. The role of botulinum toxin A in treating neurogenic bladder. Transl Androl Urol 2016;5:63-71.

41. Peyronnet B, Gamé X, Vurture G, Nitti VW, Brucker BM. Botulinum toxin use in neurourology. Rev Urol 2018;20:84-93.

42. Brindley GS. The first 500 patients with sacral anterior root stimulator implants: general description. Paraplegia 1994;32:795-805.

43. Krasmik D, Krebs J, van Ophoven A, Pannek J. Urodynamic results, clinical efficacy, and complication rates of sacral intradural deafferentation and sacral anterior root stimulation in patients with neurogenic lower urinary tract dysfunction resulting from complete spinal cord injury. Neurourol Urodyn 2014;33:1202-6.

44. Martens FM, den Hollander PP, Snoek GJ, Koldewijn EL, van Kerrebroeck PE, et al. Quality of life in complete spinal cord injury patients with a Brindley bladder stimulator compared to a matched control group. Neurourol Urodyn 2011;30:551-5.

45. Benard A, Verpillot E, Grandoulier AS, Perrouin-Verbe B, Chêne G, et al. Comparative cost-effectiveness analysis of sacral anterior root stimulation for rehabilitation of bladder dysfunction in spinal cord injured patients. Neurosurgery 2013;73:600-8.

46. Herschorn S, Bailly GG. Urinary diversion. In: Corcos J, Ginsburg D, Karsenty G, editors. Textbook of the neurogenic bladder. 3rd ed. Boca Raton, FL, USA: CRC Press; 2015. p. 545-61.

47. Johnson EU, Singh G. Long-term outcomes of urinary tract reconstruction in patients with neurogenic urinary tract dysfunction. Indian J Urol 2013;29:328-37.

48. Gurung PM, Attar KH, Abdul-Rahman A, Morris T, Hamid R, et al. Long-term outcomes of augmentation ileocystoplasty in patients with spinal cord injury: a minimum of 10 years of follow-up. BJU Int 2012;109:1236-42.

49. Michel F, Ciceron C, Bernuz B, Boissier R, Gaillet S, et al. Botulinum toxin type A injection after failure of augmentation enterocystoplasty performed for neurogenic detrusor overactivity: preliminary results of a salvage strategy. The ENTEROTOX study. Urology 2019;129:43-7.

50. Atan A, Konety BR, Nangia A, Chancellor MB. Advantages and risks of ileovesicostomy for the management of neuropathic bladder. Urology 1999;54:636-40.

51. Guillot-Tantay C, Chartier-Kastler E, Perrouin-Verbe MA, Denys P, Léon P, et al. Complications of non-continent cutaneous urinary diversion in adults with spinal cord injury: a retrospective study. Spinal Cord 2018;56:856-62.

52. Schwartz SL, Kennelly MJ, McGuire EJ, Faerber GJ. Incontinent ileo-vesicostomy urinary diversion in the treatment of lower urinary tract dysfunction. J Urol 1994;152:99-102.

53. Atan A, Konety BR, Nangia A, Chancellor MB. Advantages and risks of ileovesicostomy for the management of neuropathic bladder Urology 1999;54:636-40.

54. Hellenthal NJ, Short SS, O’Connor RC, Eandi JA, Yap SA, et al. Incontinent ileovesicostomy: long-term outcomes and complications. Neurourol Urodyn 2009;28:483-6.

55. Leng WW, Faerber G, Del Terzo M, McGuire EJ. Long-term outcome of incontinent ileovesicostomy management of severe lower 
urinary tract dysfunction. J Urol 1999;161:1803-6.

56. Tan HJ, Stoffel J, Daignault S, McGuire EJ, Latini JM. Ileovesicostomy for adults with neurogenic bladders: complications and potential risk factors for adverse outcomes. Neurourol Urodyn 2008;27:238-43.

57. Ginsberg D. The epidemiology and pathophysiology of neurogenic bladder. Am J Manag Care 2013;19:s191-6.

58. Myers JB, Lenherr SM, Stoffel JT, Elliott SP, Presson AP, et al; Neurogenic Bladder Research Group. Patient reported bladder related symptoms and quality of life after spinal cord injury with different bladder management strategies. J Urol 2019;202:574-84.

59. Adriaansen JJ, van Asbeck FW, Tepper M, Faber WX, Visser-Meily JM, et al. Bladder-emptying methods, neurogenic lower urinary tract dysfunction and impact on quality of life in people with long-term spinal cord injury. J Spinal Cord Med 2017;40:43-53.

60. Gamé X, Peyronnet B, Cornu JN. Fesoterodine: pharmacological properties and clinical implications. Eur J Pharmacol 2018;833:155-7. 